\title{
Correction to: Towards new e-Infrastructure and e-Services for Developing Countries
}

\author{
Rafik Zitouni (1D, Amreesh Phokeer(D), Josiah Chavula(D, \\ Ahmed Elmokashfi (D), Assane Gueye (D), and Nabil Benamar (D)
}

\section{Correction to: \\ R. Zitouni et al. (Eds.): Towards new e-Infrastructure and e-Services for Developing Countries, LNICST 361, https://doi.org/10.1007/978-3-030-70572-5}

In the original version of these proceedings, the affiliation of the volume editor Assane Gueye displayed in the frontmatter was incorrect. This has been corrected. 